\title{
Unusual Pungency from Extra-Virgin Olive Oil Is Attributable to Restricted Spatial Expression of the Receptor of Oleocanthal
}

\author{
Catherine Peyrot des Gachons, ${ }^{1}$ Kunitoshi Uchida, ${ }^{3,4}$ Bruce Bryant, ${ }^{1}$ Asako Shima, ${ }^{3}$ Jeffrey B. Sperry, ${ }^{2}$ \\ Luba Dankulich-Nagrudny, ${ }^{1}$ Makoto Tominaga, ${ }^{3,4}$ Amos B. Smith III, ${ }^{1,2}$ Gary K. Beauchamp, ${ }^{1}$ and Paul A. S. Breslin ${ }^{1,5}$ \\ ${ }^{1}$ Monell Chemical Senses Center and ${ }^{2}$ Department of Chemistry, University of Pennsylvania School of Medicine, Philadelphia, Pennsylvania 19104, ${ }^{3} 0 k a z a k i$ \\ Institute for Integrative Bioscience, Okazaki 444-8787, Japan, ${ }^{4}$ Department of Physiological Sciences, Graduate University for Advanced Studies, Okazaki \\ 444-8585, Japan, and 5Department of Nutritional Sciences, Rutgers University School of Environmental and Biological Sciences, New Brunswick, New \\ Jersey 08901
}

Oleocanthal, a major phenolic compound in extra-virgin olive oil with antiinflammatory properties, elicits an unusual oral pungency sensed almost exclusively in the throat. This contrasts with most other common oral irritants, such as cinnamaldehyde, capsaicin, and alcohol, which irritate mucus membranes throughout the oral cavity. Here, we show that this rare irritation pattern is a consequence of both the specificity of oleocanthal for a single sensory receptor and the anatomical restriction of this sensory receptor to the pharynx, within the oral cavity. We demonstrate, in vitro, that oleocanthal selectively activates the hTRPA1 channel in HEK 293 cells and that its ability to excite the trigeminal nervous system in rodents requires a functional TRPA1. Moreover, we similarly demonstrate that the over-the-counter analgesic, ibuprofen, which elicits the same restricted pharyngeal irritation as oleocanthal, also specifically excites rodent sensory neurons via TRPA1. Using human sensory psychophysical studies and immunohistochemical TRPA1 analyses of human oral and nasal tissues, we observe an overlap of the anatomical distribution of TRPA1 and the regions irritated by oleocanthal in humans. These results suggest that a TRPA1 (ANKTM1) gene product mediates the tissue sensitivity to oleocanthal within the oral cavity. Furthermore, we demonstrate that, despite the fact that oleocanthal possesses the classic electrophilic reactivity of many TRPA1 agonists, it does not use the previously identified activation mechanism via covalent cysteine modification. These findings provide an anatomical and molecular explanation for a distinct oral sensation that is elicited by oleocanthal and ibuprofen and that is commonly experienced around the world when consuming many extra-virgin olive oils.

\section{Introduction}

The main source of fat in the Mediterranean diet is olive oil, the constituents of which play a central role in the health benefits of the diet (Perez-Jimenez et al., 2005). The beneficial constituents in olive oil include phenolic compounds (Carluccio et al., 2003). These phenolic compounds also underlie several of the noteworthy sensory characteristics of extra-virgin olive oils such as bitter-

Received March 17, 2010; revised 0ct. 17, 2010; accepted Nov. 3, 2010.

This work was supported by National Institutes of Health (NIH) Grant DC02995 (P.A.S.B.), NIH Grant DC006760 (P.A.S.B., G.K.B.), and NIH Grant GM29028 (A.B.S.). J.B.S. was supported by NIH-Ruth L. Kirschstein National Research Service Award FCA121716A. Confocal microscopy was supported by National Science Foundation Grant DBI-0216310 (N. Rawson). TRPA1 knock-out mice were generously provided by David Corey and Kelvin Kwan from Harvard University (Cambridge, MA). The following reagents were provided as gifts: human TRPA1 (gift from Dr. A. Patapoutian, The Scripps Institute, La Jolla, CA), human TRPV1 (from Dr. Y. Mori, Kyoto University, Kyoto, Japan), human TRPV2 (from Dr. S. Wakabayashi, National Cardiovascular Center Research Institute, Osaka, Japan), human TRPV4 (from Dr. W. Leidtke, Duke University, Durham, NC), rat TRPV1, rat TRPV2, rat TRPM8 (from Dr. D. Julius, University of California, San Francisco, San Francisco, CA), and rat TRPV4 or mouse TRPV3 (from Dr. M. Caterina, The Johns Hopkins University, Baltimore, MD). We thank N. Rawson and K. Yee for assistance with nasal biopsy tissue and H. Ozdener for help with immunohistochemistry experiments. We also thank K. Plank for assistance with mouse colony maintenance.

Correspondence should be addressed to either Gary K. Beauchamp or Paul A. S. Breslin, Monell Chemical Senses Center, 3500 Market Street, Philadelphia, PA 19104. E-mail: beauchamp@monell.org or breslin@monell.org.

DOI:10.1523/JNEUROSCI.1374-10.2011

Copyright $\odot 2011$ the authors $\quad 0270-6474 / 11 / 310999-11 \$ 15.00 / 0$ ness and a prized sensory attribute, an unusual pungency restricted to the throat that often leads to coughing and throat clearing. Indeed, high-quality extra-virgin olive oils are sometimes referred to as "one cough" or "two cough" oils (the latter being more highly prized) because of this peculiar pungency. The only other compounds known to trigger this restricted pharyngeal irritation is the antiinflammatory drug ibuprofen (IBU) and its congeners (Breslin et al., 2001).

The principal molecule responsible for this pharyngeal pungency in extra-virgin olive oil is the phenolic compound (-)-oleocanthal (OC) [(-)-deacetoxy-dialdehydic ligstroside aglycone] (Andrewes et al., 2003; Beauchamp et al., 2005). The reason why the sensory characteristics of OC are so distinctive is unknown. There are many well characterized oral irritants, especially from chili peppers and horseradish, but none has this unusually localized sensation.

Irritation sensations, such as the characteristic pharyngeal sting of OC, arise from stimulation of nonspecialized nerve endings in the epithelium. Free nerve endings signal a wide range of endogenous and environmental stimuli such as protons, pressure, temperature, and nociceptive agents. The transient receptor potential (TRP) family of ion channels plays a prominent role in this signaling (Clapham, 2003). The thermo-TRP channels 
(TRPV1-TRPV4, TRPM8, and TRPA1), in particular, are expressed in keratinocytes and primary sensory neurons of the nociceptive pathway responsible for sensations of irritation, and have been shown to participate in the transduction of pain induced by thermal, mechanical, and chemical stimuli (Levine and Alessandri-Haber, 2007). Here, we demonstrate that both OC and ibuprofen selectively and robustly activate TRPA1, and we explain the mechanisms underlying the sensory properties of these compounds from human sensory, molecular, and anatomical perspectives.

\section{Materials and Methods}

Trigeminal neuron culture and calcium imaging. Rat and mouse trigeminal ganglia were collected from anesthetized animals (females and males used in equal ratio) under a protocol approved by the Institutional Animal Care and Use Committee of the Monell Chemical Senses Center and analyzed by fura-2 AM ratiometric calcium imaging. Neurons were dissociated in HBSS with trypsin $(0.0625 \%)$ for 15 min and collagenase (1 $\mathrm{mg} / \mathrm{ml})$ and DNase $(0.1 \mathrm{mg} / \mathrm{ml})$ for $1 \mathrm{~h}$, and they were separated from myelin/debris using a $15 / 30 / 60 \%$ Percoll gradient. The neurons were plated on poly-L-lysine/laminin-coated coverslips in modified Neurobasal medium supplemented with B27, $100 \mathrm{ng} / \mathrm{ml} \mathrm{NGF}$, and kept at $37^{\circ} \mathrm{C}$ and $5 \% \mathrm{CO}_{2}$. After $18 \mathrm{~h}$ incubation, neurons were loaded with $5 \mu \mathrm{M}$ fura-2 AM using $80 \mu \mathrm{g} / \mathrm{ml} \mathrm{F-127}$ pluronic acid for $1 \mathrm{~h}$. Intracellular calcium was measured ratiometrically using excitation at 340 and 380 $\mathrm{nm}$ and emission at $510 \mathrm{~nm}$. During experiments, cells were continuously superfused with mammalian Ringer's solution (containing $120 \mathrm{~mm} \mathrm{NaCl}, 5 \mathrm{~mm} \mathrm{KCl}, 1 \mathrm{~mm} \mathrm{CaCl}, 1 \mathrm{~mm} \mathrm{MgCl}$, $5 \mathrm{~mm}$ HEPES, pH $7.34)$ at $31-32^{\circ} \mathrm{C}$ into which solutions of test compounds were periodically introduced. The criterion used to determine a "response" to a stimulus is an increase of the average peak fluorescence amplitude $>0.2$ units.

Human embryonic kidney-derived 293 cell experiments. Human embryonic kidney-derived 293 (HEK 293) cells were maintained in DMEM (supplemented with 10\% fetal bovine serum, penicillin, streptomycin, and L-glutamine) and transfected with $1 \mu \mathrm{g}$ of human TRPA1 (gift from Dr. A. Patapoutian, The Scripps Institute, La Jolla, CA), human TRPV1 (from Dr. Y. Mori, Kyoto University, Kyoto, Japan), human TRPV2 (from Dr. S. Wakabayashi, National Cardiovascular Center Research Institute, Osaka, Japan), human TRPV4 (from Dr. W. Leidtke, Duke University, Durham, NC), rat TRPV1, rat TRPV2, rat TRPM8 (from Dr. D. Julius, University of California, San Francisco, San Francisco, CA), rat TRPV4, or mouse TRPV3 (from Dr. M. Caterina, The Johns Hopkins University, Baltimore, MD) cDNA. One microgram of expression vector and $0.1 \mu \mathrm{g}$ of pGreen Lantern $1 \mathrm{cDNAs}$ in Opti-MEM medium (Invitrogen) were transfected to HEK 293 cells using Lipofectamine Plus reagent (Invitrogen). After incubating for 3-4 h, cells were reseeded on coverslips and further incubated at $37^{\circ} \mathrm{C}$ in $5 \% \mathrm{CO}_{2}$. One day after transfection, whole-cell patch-clamp recordings were performed. The standard bath solution for patch-clamp experiments contained the following (in mM): $140 \mathrm{NaCl}, 5 \mathrm{KCl}, 2 \mathrm{MgCl}_{2}, 2 \mathrm{CaCl}_{2}, 10$ HEPES, 10 glucose, $\mathrm{pH} 7.4$ (with $\mathrm{NaOH}$ ). The pipette solution contained the following (in $\mathrm{mm}$ ): 140 $\mathrm{KCl}, 5$ EGTA, 10 HEPES, pH 7.4 (with $\mathrm{KOH}$ ). Data from whole-cell voltage-clamp recordings were sampled at $10 \mathrm{kHz}$ and filtered at 5 $\mathrm{kHz}$ for analysis (Axon 200B amplifier with pCLAMP software; Molecular Devices). The voltage-ramp pulse $(400 \mathrm{~ms})$ from -100 to $+100 \mathrm{mV}$ was applied to the patch-clamped cell held at $-60 \mathrm{mV}$ every $5 \mathrm{~s}$. Whole-cell patch-clamp recordings were performed $1 \mathrm{~d}$ after transfection of HEK 293 cells. All the experiments were performed at room temperature.

A double cysteine mutant of mouse TRPA1 (C422S/C622S) was generated by cysteine-serine substitutions at $\mathrm{C} 422$ and $\mathrm{C} 622$, residues that are thought to be covalently modified by several electrophilic agonists, in the N-terminal domain. These mutations were made by using a modified QuikChange site-directed mutagenesis method (Stratagene). Briefly, PCR was performed using two residues of mouse TRPA1 expression vector divided at the ClaI (New England Biolabs) site as templates (the former for C422S, the latter for C622S), two synthetic oligonucleotide primers contain- ing specific mutations [C422S-sense (S) and -antisense (AS), 5' -CATTATGCCTCTAGGCAGGGG- $3^{\prime}$ and $5^{\prime}$-CCCCTGCCTAGAGGCATAATG- ${ }^{\prime}$; C622S-S and -AS, 5'-CCCGAGTCCATGAAAGTTCTT-3' and 5'-AAGAACTTTCATGGACTCGGG-3'], and PrimeSTAR HS DNA polymerase (Takara). The PCR products were digested with DpnI (New England Biolabs) at $37^{\circ} \mathrm{C}$ for $1 \mathrm{~h}$ and transformed into $\mathrm{DH} 5 \mathrm{a}$ competent cells. The entire sequence including desired substitution in the mutants was confirmed. TRPA1 mutant (C422S/C622S) was constructed by combining these two mutants at the ClaI site.

Human testing. Under protocols approved by the Office of Regulatory Affairs at the University of Pennsylvania, volunteers were asked to evaluate the irritation elicited by the test compounds using a computerized general Labeled Magnitude Scale (gLMS) (Green et al., 1996). On this gLMS, subjects rated the perceived intensity along a vertical axis lined with adjectives: barely detectable, 1; weak, 5; moderate, 16; strong, 33; very strong, 51; strongest imaginable, 96 . The gLMS shows only adjectives, not numbers, to the subjects, but the experimenter receives numerical data from the computer program. Each subject was tested only twice a day with one sample and with at least $2 \mathrm{~h}$ separating each test (Brand and Jacquot, 2002). All tests were performed in duplicate, and stimuli were presented in random order.

For testing irritation on the tongue, subjects immersed their tongue into a medicine cup containing $25 \mathrm{ml}$ of solution for $45 \mathrm{~s}$. For testing irritation in the throat, the same subjects placed $3.5 \mathrm{ml}$ of the solutions in their mouth, holding it for $3 \mathrm{~s}$ and then swallowing it. After $45 \mathrm{~s}$, subjects were asked to rate the peak throat irritation intensity. For testing irritation in the nose, subjects $(n=14)$ applied $0.3 \mathrm{ml}$ of the test stimuli dissolved in saline solution (SaltAire sinus relief) with a metered nasal spray device (Total Pharmacy Supply). After 30 s, subjects were asked to rate the peak nasal irritation intensity on the gLMS.

Immunohistochemistry. The biopsy of fungiform papillae from the front edge of three healthy volunteers' tongues and the nasal biopsies from middle turbinate of four other healthy volunteers were excised under protocols approve by the Office of Regulatory Affairs at the University of Pennsylvania. Additionally, fresh human tongue and pharyngeal tissue were obtained from the cadaver of an accident victim, who was healthy before the accident (a nonclinical patient), and were provided by National Disease Research Interchange. Thus, tissues that are OCsensitive and OC-insensitive were obtained from eight different individuals for immunohistochemical analysis of TRPA1 expression in sensory neurons. All tissues were fixed in 4\% paraformaldehyde in PBS for $1-2 \mathrm{~h}$, and then cryoprotected in sucrose series. The entire biopsies were cut into $10 \mu \mathrm{m}$ sections and placed onto StarFrost adhesive slides (Mercedes Medical) and stored at $-30^{\circ} \mathrm{C}$. Slides were removed from $-30^{\circ} \mathrm{C}$ and dried at $40^{\circ} \mathrm{C}$ for $20 \mathrm{~min}$, and then they were washed one time for $10 \mathrm{~min}$ in PBS, pH 7.4. To block nonspecific binding, sections were incubated at room temperature with SuperBlock blocking buffer (Pierce; 37517) overnight. Then, sections were incubated with primary antibody diluted in $10 \%$ SuperBlock for $2 \mathrm{~d}$ at $4^{\circ} \mathrm{C}$ in humidified chamber followed by secondary antibody conjugated to fluorescence probe (Alexa Fluor 488 goat anti-mouse IgG or Alexa Fluor 633 goat anti-rabbit IgG; Invitrogen) in $1 \%$ SuperBlock for $1 \mathrm{~h}$ at room temperature. The sections then were washed twice with PBS followed with milliQ water, and then mounted with Vectashield or Vectashield with DAPI (Vector Laboratories). Control experiments were performed using an excess of the appropriate homolog peptide antigen to absorb the primary antibodies and thus confirm a specific immunoreaction. Antibodies used included antihuman TRPA1 polyclonal made in rabbit (dilution, 1:100; from MBL; LS-A9097) and monoclonal anti-human PGP9.5 made in mouse (AbD Serotec) or monoclonal anti-syntaxin made in mouse (Sigma-Aldrich). Images were taken using a Leica TCS SP2 spectral confocal microscope (Leica Microsystems). Quantification of TRPA1 antibody fluorescence was evaluated by counting positives cells on analyzed slides for which surface area of tissues was determined with the confocal microscope software. TRPA1 quantification is expressed as number of cells per square millimeter.

Compounds. All the compounds were purchased at Sigma-Aldrich, except 2-(1,3-dimethyl-2,6-dioxo-1,2,3,6-tetrahydro-7H-purin-7-yl)$N$-(4-isopropylphenyl)acetamide (HC-030031), which was obtained 

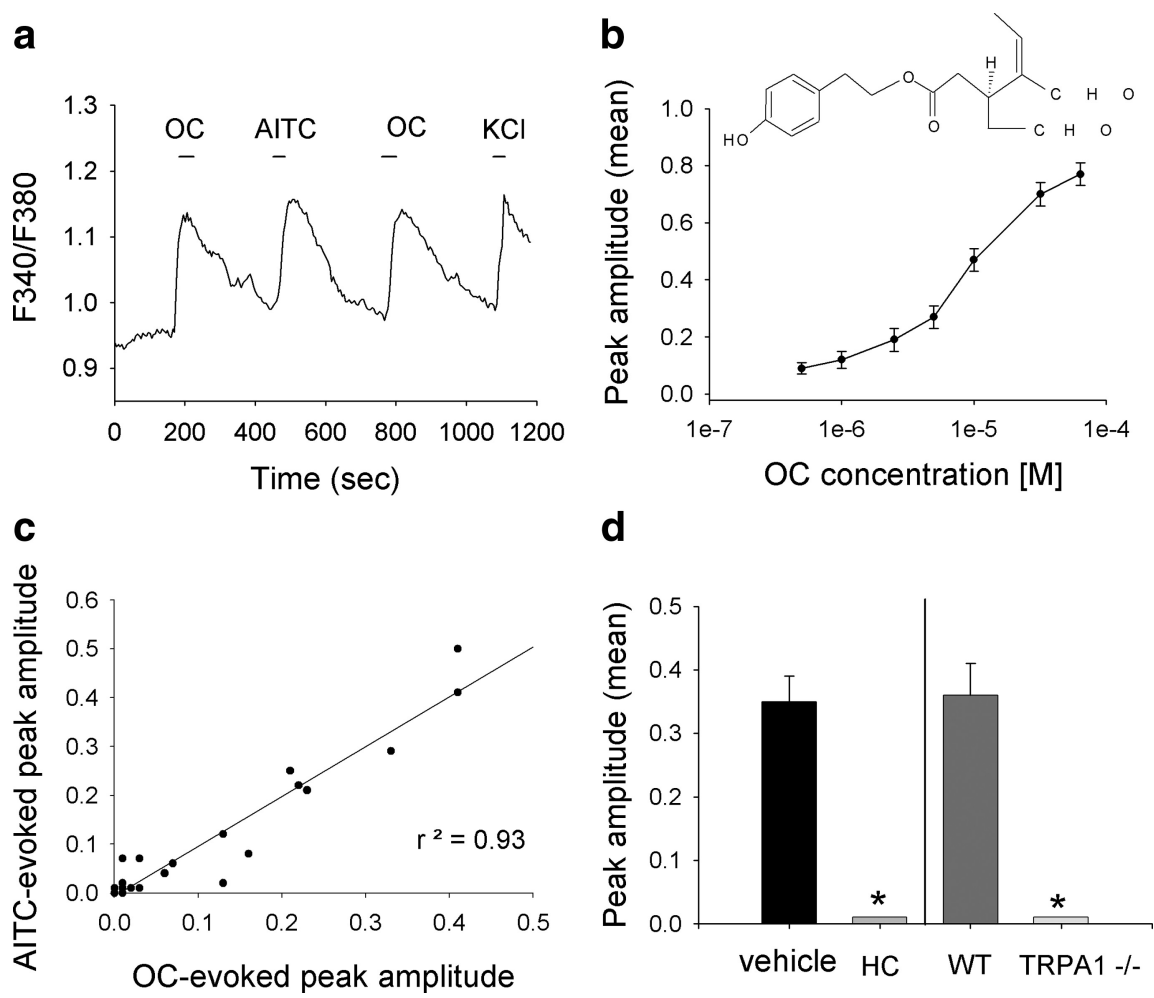

d

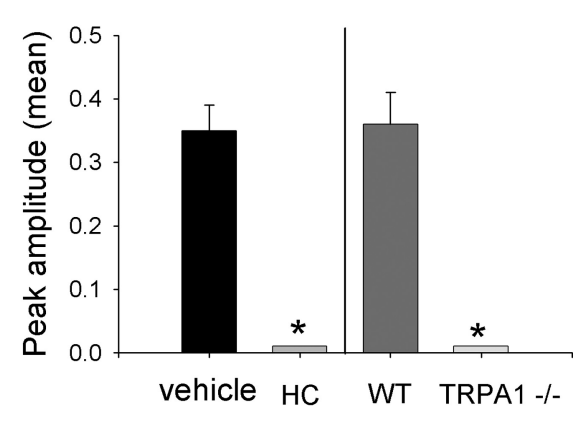

Figure 1. Oleocanthal excites trigeminal neurons through TRPA1 channel activation. $\boldsymbol{a}, 0 C(5 \mu \mathrm{M})$ evokes calcium influx into cultured rat trigeminal neurons as assessed by fura- 2 ratiometric imaging $\left(F_{340} / F_{380}\right)$. In $\boldsymbol{a}$, the representative trace of one neuron shows that cells sensitive to 0 C are also activated by AITC $(50 \mu \mathrm{m})$. The horizontal bars indicate the duration of compound application. The $40 \mathrm{~mm} \mathrm{KCl}$ solutions were applied as a control for neuronal activity. $\boldsymbol{b}$, Dose-response curve for $O C$-evoked responses in rat trigeminal neurons. The curve was generated by averaging the peak amplitude of the responses (fura- 2 ratio) of all the $O C$-sensitive cells ( $n>18$ /data points). $O C$ chemical structure is indicated on the graph. $\boldsymbol{c}$, Sensitivity to $O C(5 \mu \mathrm{M})$ is correlated to sensitivity to AITC $(50 \mu \mathrm{M})$ in trigeminal neurons $(n>40$ per experiment). $\boldsymbol{d}$, Rodent trigeminal neurons deprived of functioning TRPA1 are unresponsive to OC. HC-030031 (HC) (20 $\mu \mathrm{m})$ inhibited $5 \mu \mathrm{M}$ $O C$-evoked rat trigeminal neuron activation (examined cells, $n=191)$ (left) and neurons from TRPA ${ }^{-1-}$ mice $(n=187$, from 5 mice) are not excited by $0 C$ (right). ${ }^{*} p<0.05$ versus control [vehicle for left panel; wild-type (WT) for right panel], $t$ test. Error bars indicate SEM.

from ChemBridge, and oleocanthal and analogs, which were synthesized as described by Smith et al. $(2005,2007)$.

Statistical analysis. Data in figures are presented as mean \pm SEM. Statistical significance was evaluated using Student's unpaired $t$ tests. Statistical significance was set at a value of $p<0.05$.

\section{Results}

TRPA1 transduces the neuronal signal of OC

We first examined whether OC directly excites primary sensory neurons by using fura- 2 ratiometric calcium imaging on acutely cultured rat trigeminal ganglion neurons. Application of OC elicited robust calcium influx (Fig. $1 a$ ) into $\sim 30 \%$ of the trigeminal neurons, in a concentration-dependent manner (Fig. 1b). Comparison of the trigeminal neuron activation profile of OC (distribution and intensity of intracellular calcium influx) with more commonly used oral irritants such as menthol, allyl isothiocyanate (AITC), or capsaicin, which stimulate TRPM8 (McKemy et al., 2002; Peier et al., 2002), TRPA1 (Bandell et al., 2004; Jordt et al., 2004), and TRPV1 (Caterina et al., 1997) receptors, respectively, demonstrated that the populations of rat neurons robustly activated by OC were sensitive to AITC $(50 \mu \mathrm{M})$ and the magnitude of the calcium influx elicited by these stimuli were tightly correlated (Fig. 1c), whereas no correlation was observed with other irritant response profiles (supplemental Fig. 1, available at www.jneurosci.org as supplemental material). Using the re- sponse criterion of a change of peak fluorescence amplitude $>0.2$ units, in these experiments, $100 \%$ of the AITC-sensitive neurons responded to OC and only $30 \%$ of the capsaicin-sensitive neurons responded to OC.

To test the hypothesis that OC acts on the TRPA1 ion channel in trigeminal neurons, we used the selective TRPA1 blocker HC-030031 (McNamara et al., 2007) and additionally examined the response profiles of trigeminal neurons from TRPA1deficient (knock-out) mice. OC-evoked calcium increases were totally abolished by $20 \mu \mathrm{M} \mathrm{HC}-030031$ and neurons from TRPA1-null (-/-) mice were utterly unresponsive to OC (Fig. 1d). As expected, in both experiments the sensitivity to capsaicin was retained (supplemental Fig. 2, available at www.jneurosci.org as supplemental material). The complete loss of sensitivity to OC implicates TRPA1 as the requisite native target in sensory neurons.

To confirm the activation and specificity of OC on TRPA1, we used patch-clamp recordings and calcium imaging on heterologously expressed TRP channels. All the known thermo-TRP channels (TRPV1TRPV4, TRPM8, and TRPA1) that are involved in irritation transduction were tested. OC induced robust currents in HEK 293 cells expressing the human TRPA1 channel (Fig. 2a), in the presence or absence of external calcium, but not in human TRPV1, TRPV2, and TRPV4 (Fig. 2b). OC also did not excite HEK cells expressing rodent TRPV1, 2, 3, 4, and TRPM8 (supplemental Fig. 3, available at www.jneurosci.org as supplemental material). We established the $\mathrm{EC}_{50}$ of OC at $2.8 \mu \mathrm{M}$ in hTRPA1 and verified that OC-elicited currents were reversibly inhibited by the TRPA1 blocker HC030031 (supplemental Fig. 4, available at www.jneurosci.org as supplemental material). Thus, the neuronal signal of OC is transduced by TRPA1 and no other thermo-TRP channels.

\section{Ibuprofen, another restricted throat irritant like OC, selectively activates TRPA1}

The phenylpropanoic nonsteroidal antiinflammatory drugs (NSAIDs), such as IBU, trigger a pharyngeal irritation remarkably similar in quality and restricted location to that elicited by OC (Breslin et al., 2001). Demonstration that IBU, like OC, selectively activates TRPA1 in sensory neurons would reinforce the hypothesis that this receptor mediates the unusual restricted pharyngeal pungency in vivo. Application of IBU (10 mM) elicited robust calcium influx into cultured trigeminal neurons (Fig. $3 a$ ) in a concentration-dependent manner (Fig. 3b). Unfortunately, the high IBU concentrations $(>30 \mathrm{~mm}$ ) required to complete the dose-response curve presented in Figure $3 b$ did not permit us to reach saturation, as the increase of the ionic strength and osmolarity of the medium affected cell viability. It is worth noting that all dissociated trigeminal neurons exposed to IBU showed some small intracellular calcium increase, dependent on the presence 
a

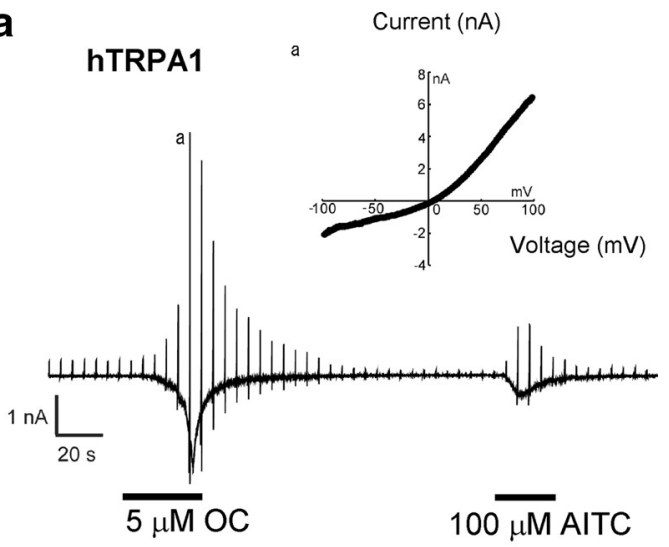

b

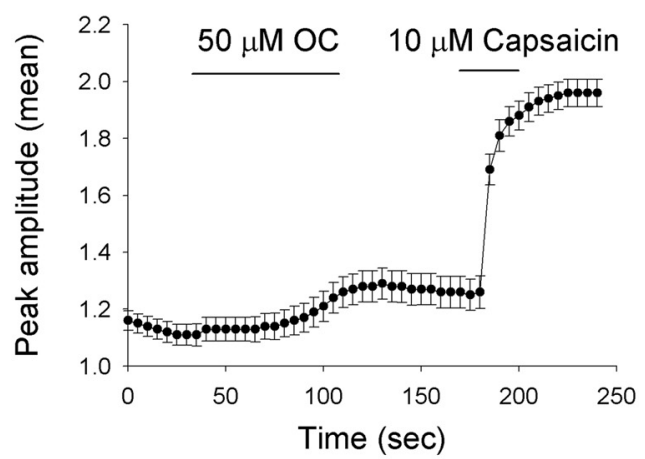

hTRPV2

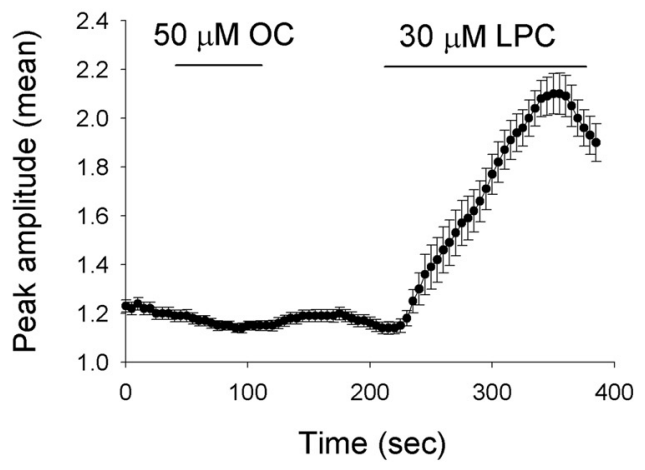

hTRPV4

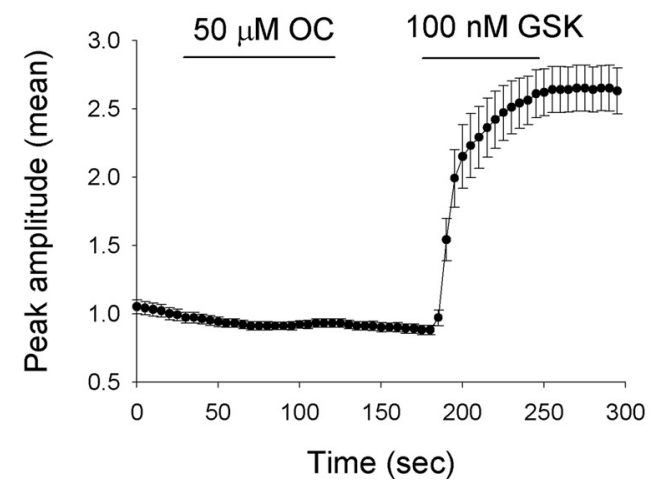

Figure 2. Oleocanthal exclusively activates TRPA1 in HEK 293 cells expressing human TRP channels. $\boldsymbol{a}$, OC activates hTRPA1-expressing HEK 293 cells. Representative whole-cell current trace activated by $O C(5 \mu \mathrm{M})$ and AITC $(100 \mu \mathrm{M})$ in the presence of extracellular $\mathrm{Ca}^{2+} \cdot V_{\mathrm{h}}=$ $-60 \mathrm{mV}$. The horizontal bars indicate the duration of compound application. The currentvoltage ( $I-V$ ) curves were expanded from the current response indicated (a) in the traces. $\boldsymbol{b}$, of extracellular calcium (Fig. $3 c$, gray circle). But robust responses to IBU (with peak magnitudes $>0.2$ units) were only observed in neurons that responded to OC. Also, the magnitudes of activation by these two compounds were correlated (Fig. 3c). This suggests that OC and IBU act on the same receptor(s). Comparable with OC, the selective TRPA1 blocker HC-030031 (20 $\mu \mathrm{M})$ strongly suppressed the intracellular calcium increase induced by $10 \mathrm{~mm}$ IBU that occurred in the OC-sensitive neurons. Only the low-level basal calcium influx induced by IBU, ubiquitously found in all the neurons, and not considered a true response (peak magnitude mean, $<0.2$ units), remained (Fig. $3 e$, left). Similar results were obtained with TRPA1-deficient trigeminal neurons from knock-out mice (Fig. 3e, right). These results strongly suggest that IBU elicits neuronal responses by acting on TRPA1, but the data are less clear than with OC. To confirm that TRPA1 is required for IBU-evoked neuronal response, we conducted current measurements in sensory neurons [dorsal root ganglion (DRG) neurons]. The data in Figure $3 d$ show that when TRPA1 is absent (AITC insensitive), the sensory neuron is not activated. Indeed, there is no current recorded after IBU exposure (Fig. $3 d$, bottom). Whereas when TRPA1 is present (AITC positive), the sensory neuron is activated by IBU (Fig. $3 d$, top). In total, 20 sensory neurons have been tested. These results confirm that IBU selectively activates TRPA1 (directly or indirectly) and no other receptor in sensory neurons.

In patch-clamp recordings and calcium imaging on heterologously expressed TRP channels, IBU induced robust currents in HEK 293 cells expressing human TRPA1 channel (Fig. 4a) in the presence or absence of external calcium, and had no or little effect on HEK cells expressing human TRPV1, TRPV2, TRPV4 (Fig. $4 b$ ), and rodent TRPM8 and TRPV1-4 (supplemental Fig. 3, available at www.jneurosci.org as supplemental material). In summary, these results support the conclusion that the orosensory signals of OC and IBU are mediated via the same receptor, TRPA1.

\section{OC presents a spatial irritation profile distinct from other pungent TRPA1 agonists}

Most pungent food products elicit strong sensation throughout the oral cavity; these include the plant-derived oral irritants such as isothiocyanates (mustard, winter cress), allicin (garlic), cinnamaldehyde (cinnamon bark), carvacrol (oregano), or thymol (thyme), which are all TRPA1 agonists (Bandell et al., 2004; Jordt et al., 2004; Bautista et al., 2005; Macpherson et al., 2005; Xu et al., 2006; Lee et al., 2008). There are a few possibilities as to why irritation from these stimuli is not restricted to the throat in humans as it is for OC and ibuprofen. One is that the perceptual differences between OC and other TRPA1 agonists are the result of differences in stimulus concentrations. Indeed, these irritating compounds are experienced in foods at higher concentrations (in millimolar) than the OC concentrations found in extra-virgin olive oil $(100-700 \mu \mathrm{M})$. To test this hypothesis, we compared the irritation sensation characteristics of a commercial extra-virgin olive oil with those of a horseradish solution ( $1.25 \mathrm{~g}$ dissolved in $100 \mathrm{ml}$ of milliQ water), both sources of TRPA1 agonists (OC and

HEK 293 cells expressing hTRPV1, hTRPV2, and hTRPV4 are not excited by OC. Fifty micromolar 0 C does not evoke calcium influx into hTRPV1 $(n=100), 2(n=77)$, and $4(n=39)$ as assessed by fura-2 ratiometric imaging $\left(F_{340} / F_{380}\right)$. The channel-specific ligands, capsaicin, lysophosphatidylcholine (LPC), and GSK1016790A, were applied as controls for activity in HEK cells expressing TRPV1, TRPV2, and TRPV4, respectively. The curves in $\boldsymbol{b}$ were generated using mean values of peak amplitude. Error bars indicate SEM. 
a

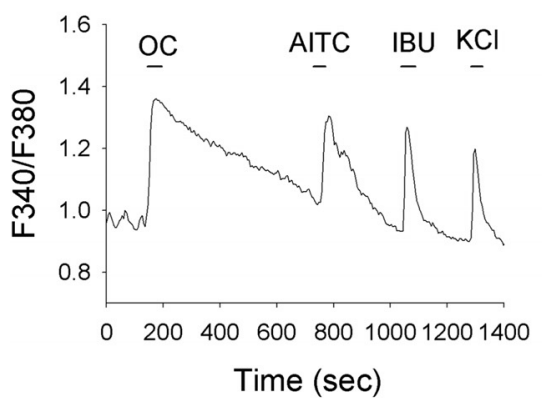

C

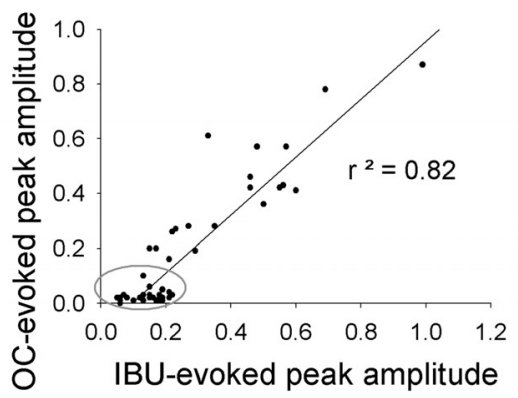

e

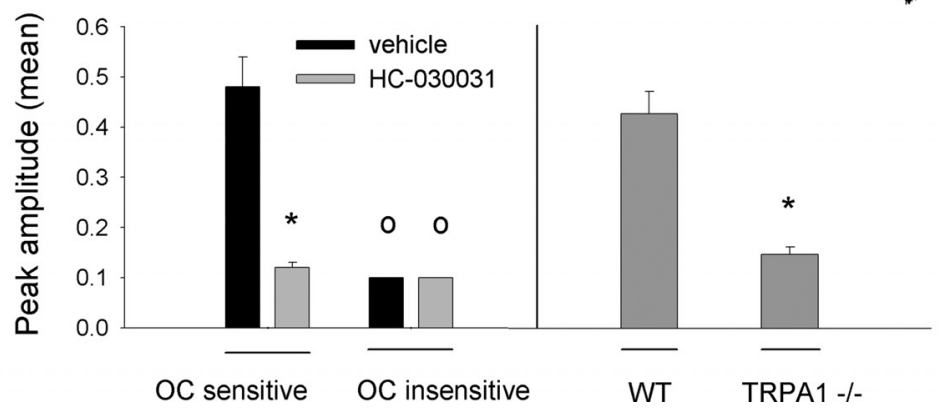

Figure 3. Ibuprofen excites trigeminal neurons through TRPA1 channel activation. $\boldsymbol{a}$, IBU (10 mm) evokes calcium influx into cultured rat trigeminal neurons as assessed by fura- 2 ratiometric imaging $\left(F_{340} / F_{380}\right)$. In $\boldsymbol{a}$, the representative trace of one neuron shows that cells sensitive to IBU are also activated by $O C(5 \mu \mathrm{m})$ and AITC (50 $\mu \mathrm{M})$. The horizontal bars indicate the duration of compound application. The $40 \mathrm{~mm} \mathrm{KCl}$ solutions were applied as a control for neuronal activity. $\boldsymbol{b}$, Dose-response curves for IBU-evoked responses in rat trigeminal neurons. The high IBU concentrations ( $>30 \mathrm{~mm}$ ) required to complete the dose-response curve did not permit to reach saturation, as the increase of the ionic strength and osmolarity of the medium affected cell viability. The curve was generated by averaging the peak amplitude of the responses (fura- 2 ratio) of all the cells ( $n>60$ per data point). IBU chemical structure is indicated on the graph. $c$, Sensitivity to 0 C and IBU is correlated in sensory neurons. The scatterplot displays relationship between $10 \mathrm{~mm} \mathrm{IBU}$ and $5 \mu \mathrm{M} O C$-evoked responses in trigeminal neurons. Each dot represents intracellular calcium increase in a single cell. Small calcium influxes induced by IBU (gray circle) were observed in all the examined cells $(n=56)$ insensitive to OC. $\boldsymbol{d}$, Representative whole-cell current traces generated in DRG neurons, in the presence of extracellular $\mathrm{Ca}^{2+}$. $V_{\mathrm{h}}=-60 \mathrm{mV}$. Ten millimolar IBU elicited current responses in sensory neurons expressing TRPA1 (AITC sensitive) (top) but not in sensory neurons lacking the TRPA1 channel (AITC insensitive) (bottom). $e$, TRPA1 is required for trigeminal neuron response to IBU. HC-030031 (HC) $(20 \mu \mathrm{m})$ decreased $10 \mathrm{~mm}$ IBU-evoked responses down to the calcium influx measured in all the 0 C-insensitive cells (examined cells, $n=55$ ) (left) and TRPA1-deficient trigeminal neurons display only small nonspecific IBU-evoked calcium influx ( $n=128$ from 5 mice) (right) similar to those observed in the 0 C-insensitive cells (left). ${ }^{*} p<0.05$ versus control [vehicle for left panel; wild-type (WT) for right panel], ${ }^{\circ} p<0.05$ versus $0 C$-sensitive cells in vehicle solution, $t$ test. Error bars indicate SEM.

tongue, whereas horseradish irritation was strongly sensed on anterior tongue (Fig. 5a). Thus, it is unlikely that the weaker anterior oral pungency of OC compared with AITC is attributable to concentrations being insufficient to stimulate strong oral pungency. The two irritants in these food products elicit very different sensory profiles although they both act on TRPA1 with comparable sensory $\mathrm{EC}_{50}$ values: $\mathrm{OC}(2.8 \mu \mathrm{M}$ for hTRPA1) and AITC (11.3 $\mu \mathrm{m}$ for hTRPA1) (Chen et al., 2008).

We also determined that the viscous and hydrophobic nature of olive oil does not prevent OC from acting in the mouth by comparing the irritation location of OC dissolved in water with the irritation location of OC dissolved in corn oil. For this study, the OC concentration was set at $660 \mu \mathrm{M}$, which corresponds to the very high end of what can be found in commercial extra-virgin olive oils (Beauchamp et al., 2005). The addition of $0.25 \%$ ethanol was required to dissolve the OC in water. Because ethanol itself may be irritating at this concentration, we included a control aqueous solution containing $0.25 \%$ ethanol only. After the same protocol as the sensory study above, subjects $(n=13)$ rated the intensity of the irritation perceived either on the tip of the tongue or in the throat. As was the case for extra-virgin olive oil, OC predominantly triggered irritation in the throat compared with the anterior tongue and did this independently of the medium in which the compound was dissolved (Fig. 5b). Although it appears that OC dissolved in water elicited slight irritation on the anterior tongue, this was not significantly greater than that elicited by the alcohol vehicle control $(t$ test, $p>$ 0.05). The perceived anterior lingual irritation is, thus, likely attributable to the presence of ethanol. That OC regional irritation properties are also observed in aqueous medium is consistent with previous observations with IBU in aqueous mixtures (Breslin et al., 2001).

Another explanation for the absence of oral pungency from OC in anterior tongue could be an inability of this compound to stimulate the human trigeminal nerve. To address this hypothesis, we asked subjects $(n=11)$ to evaluate nasal irritation from OC and IBU when they were sprayed into the nares, since nasal

AITC, respectively). Human subjects $(n=12)$, while wearing nose clips to block odors and nasal irritation, were asked to rate the irritation perceived on their anterior tongue after immersing it in $25 \mathrm{ml}$ of either extra-virgin olive oil (Badalucco) or horseradish (wasabi; S\&B) solution, and the irritation perceived in their throat after swallowing $3.5 \mathrm{ml}$ of the same solutions. Although the two solutions triggered pharyngeal irritation with matching intensity, extra-virgin olive oil elicited very little pungency on the anterior irritants are detected solely by trigeminal nerve endings. Cinnamaldehyde and sucrose were also tested, as positive and negative controls for irritation sensation, respectively (Fig. 5c). As expected, sucrose solutions did not elicit irritation and cinnamaldehyde triggered concentration-dependent nasal irritation. OC and IBU induced irritation in the nose that increased monotonically with concentration, which demonstrates that they clearly activate the human trigeminal nerve in situ. Note that $60 \mu \mathrm{M}$ OC 
a

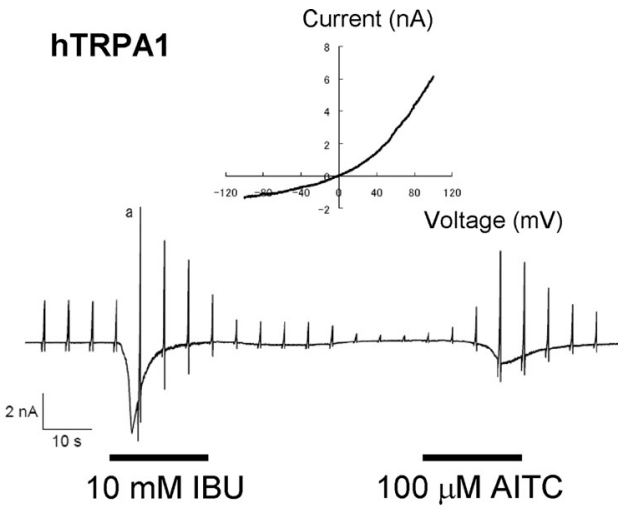

b

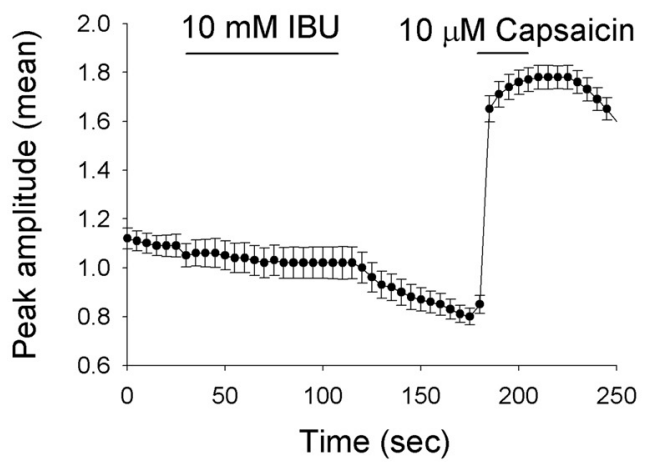

hTRPV2
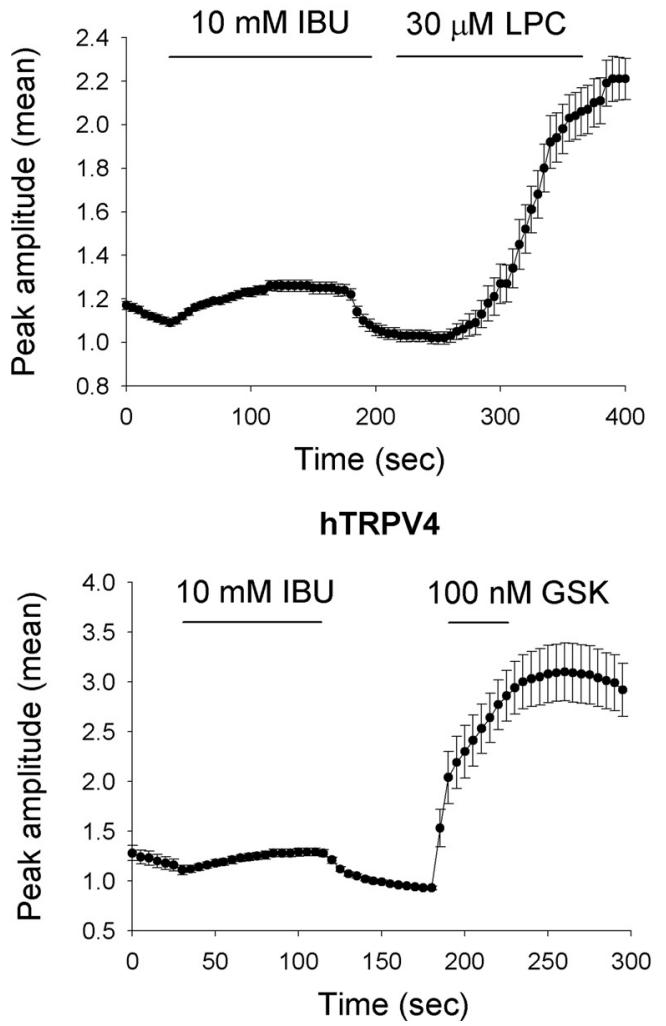

Figure 4. Ibuprofen exclusively activates TRPA1 in HEK 293 cells expressing human TRP channels. $\boldsymbol{a}$, IBU activates hTRPA1-expressing HEK 293 cells. Representative whole-cell current trace activated by IBU $(10 \mathrm{~mm})$ and AITC $(100 \mu \mathrm{m})$ in the presence of extracellular $\mathrm{Ca}^{2+} \cdot V_{\mathrm{h}}=$ $-60 \mathrm{mV} . \boldsymbol{b}$, HEK 293 cells expressing hTRPV1, hTRPV2, and hTRPV4 are not excited by IBU. Ten millimolar IBU does not evoke calcium influx into hTRPV1 $(n=95), 2(n=82)$, and $4(n=38)$ as assessed by fura- 2 ratiometric imaging $\left(F_{340} / F_{380}\right)$. The channel-specific ligands, capsaicin, elicited moderate irritation in the nose (based on sensory ratings on a general Labeled Magnitude Scale), which is $\sim 10$-fold more sensitive than the throat (Beauchamp et al., 2005). Concentrations at which humans perceive nasal irritation elicited by OC are very similar to the concentrations required to activate rat trigeminal neurons and hTRPA1 channels expressed in HEK 293 cells $(1-60 \mu \mathrm{M})$ (Fig. $5 d$ ). Hence, OC excites the human sensory neural system with high potency in nasal and pharyngeal tissues, and the absence of anterior oral pungency from $\mathrm{OC}$ is not attributable to a failure to act on trigeminal neurons in humans.

The restricted regions irritated by extra-virgin olive oil overlap with the expression pattern of the receptor of OC in the oral cavity

We hypothesized that the specific OC-responsive TRPA1 channel may be expressed less in the mandibular branch of the trigeminal nerve that innervates the anterior tongue than in nasal and pharyngeal branches. We immunohistochemically assessed TRPA1 expression in human tongue biopsies from four volunteers, in nasal biopsies from four different subjects, and in pharyngeal tissue from one subject, who also provided a tongue biopsy. In total, healthy tissues from eight subjects were analyzed for TRPA1 expression in sensory neurons of OC-sensitive tissues (nasal and pharyngeal) and OC-insensitive tissue (anterior tongue). Antisera raised against human TRPA1 in rabbits was used on human lingual fungiform papilla (Fig. 6a-f) and pharyngeal epithelium (Fig. $6 g-l$ ). Antibodies to the generic neural marker PGP9.5 indicated that both epithelia are richly innervated with free nerve endings (Fig. $6 d-j$ ). In particular, taste buds are densely innervated and are surrounded by trigeminal neural fibers passing through the epithelium in the peribud region, but none of these fibers demonstrated TRPA1 immunoreactivity on double labeling (Fig. $6 f$ ) (for large-scale fungiform papilla, see supplemental Fig. 5, available at www.jneurosci.org as supplemental material). In contrast, neuronal cells from human upper pharynx showed clear TRPA1 double immunoreactivity with the neural marker PGP9.5 (Fig. 6l). Eight to 10 slides were examined for each tissue type. For pharyngeal tissue, 80 TRPA1-positive cells per 0.12 $\mathrm{mm}^{2}$ (mean) were observed, and for lingual tissue (taste buds), 0 TRPA1-positive cells per $0.05 \mathrm{~mm}^{2}$ (mean). Immunohistochemistry performed on four humans' nasal epithelia, another tissue highly sensitive to OC irritation, led to similar results as seen in the pharynx (supplemental Fig. 6, available at www.jneurosci.org as supplemental material). TRPA1 antibody specificity was demonstrated in human tissues either treated with secondary antibodies in the absence of primary antibodies or treated with TRPA1 antibodies blocked with the TRPA1 peptide (supplemental Fig. 6, available at www.jneurosci.org as supplemental material). In addition, TRPA1-null (-/-) mice epithelium displayed minimal antibody reactivity compared with wild-type mouse lingual tissues, further supporting specificity of this TRPA1 antibody for the target protein (supplemental Fig. 7, available at www.jneurosci.org as supplemental material). (Note that, unlike humans, mice express TRPA1 robustly in lingual tissues.) These observations suggest a poor expression of the $\mathrm{OC}$ receptor on the trigeminal fibers innervating the human anterior tongue com-

lysophosphatidylcholine (LPC), and GSK1016790A, were applied as controls for activity in HEK cells expressing TRPV1, TRPV2, and TRPV4, respectively. The curves in $\boldsymbol{b}$ were generated using mean values of peak amplitude. Error bars indicate SEM. 

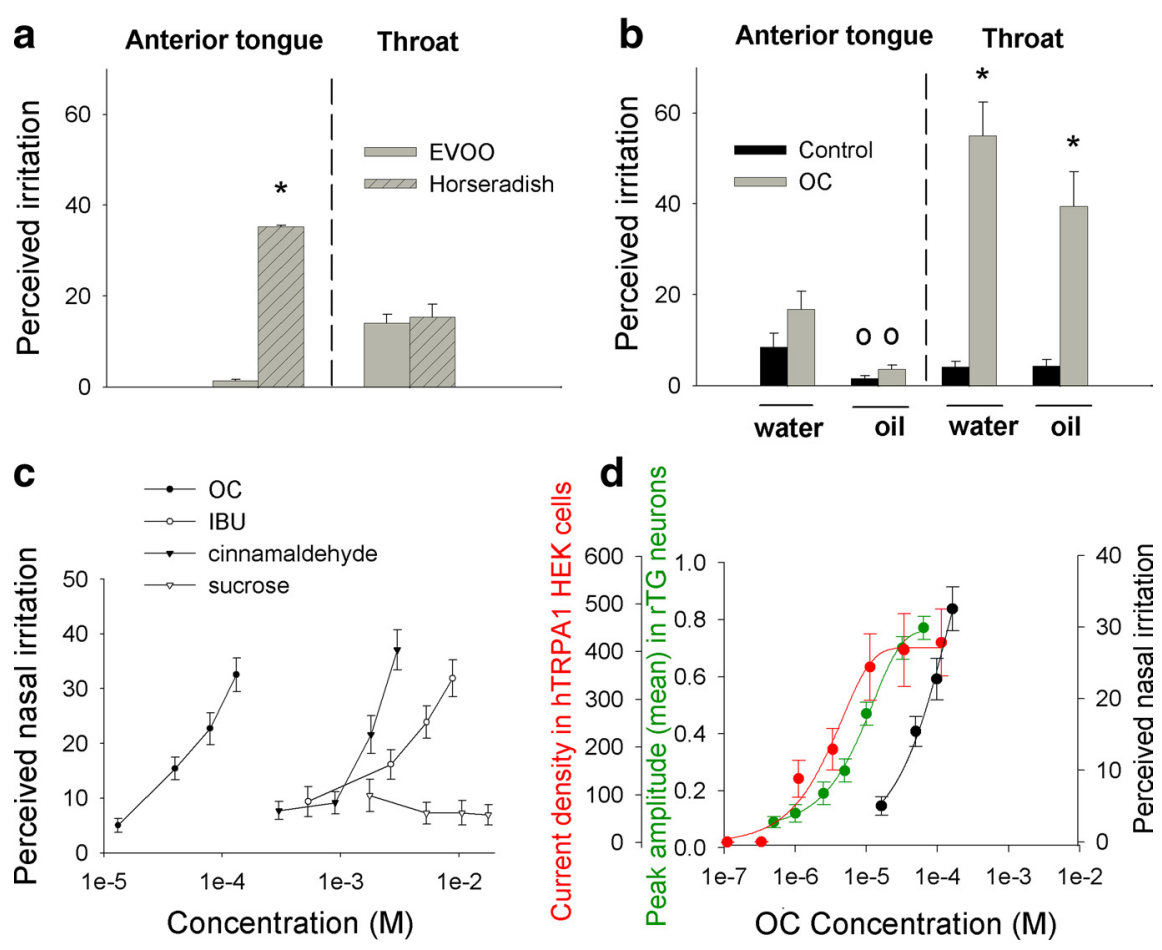

Figure 5. The human throat and nose are more sensitive than the anterior tongue to $0 \mathrm{C}$. $\boldsymbol{a}$, Irritation perceived on the anterior tongue after its immersion in either $25 \mathrm{ml}$ of an extra-virgin olive oil (EVO0) (OC source) or a horseradish solution (AITC source), and irritation perceived in the throat after swallowing $3.5 \mathrm{ml}$ of the same solutions (subjects $=12$ ). ${ }^{*} p<0.05$ versus olive oil, $t$ test. $\boldsymbol{b}$, Irritation perceived either on the anterior tongue after its immersion in $25 \mathrm{ml}$ of solution, or in the throat after swallowing $3.5 \mathrm{ml}$ of the same solutions (subjects $=13$ ). The four solutions tested were as follows: water plus $0.25 \%$ ethanol, water plus $0.25 \%$ ethanol plus $660 \mu \mathrm{M} \mathrm{OC}$, corn oil, and corn oil plus $660 \mu \mathrm{m}$ OC. The addition of $0.25 \%$ ethanol was required to dissolve $0 \mathrm{C}$ in water. ${ }^{*} p<0.05$ versus control, ${ }^{\circ} p<0.05$ versus water, $t$ test. $c$, Irritation perceived in the nares after application of $0 C$, IBU, transcinnamaldehyde, and sucrose. Each stimulus dissolved in saline solution plus $0.1 \%$ ethanol was applied in the subject nares with a nasal sprayer device (volume, $0.3 \mathrm{ml}$ ). The four concentrations used for each stimulus were tested in independent sessions and in duplicate (subjects $=11$ ). Mean intensity rating of saline solution plus $0.1 \%$ ethanol alone was similar to the sucrose solution $(=5.14)$. All perceived irritation ratings were performed on a gLMS scale. Values represent mean of gLMS ratings $\pm S E M$. $d, O C$ activation curves in cultured rat trigeminal neurons (green) and current density curves of heterologously expressed hTRPA1 channels in HEK 293 cells (red) compared with the perceived intensity curve of the compound in the nares (black). Error bars indicate SEM.

pared with human pharyngeal and nasal nerve afferents. This antibody reveals a TRPA1 anatomical distribution that overlays with the profile of localized sensory irritation observed with OC in humans. These results also suggest that some canonical TRPA1 agonists, such as AITC, may irritate the anterior tongue in humans via interaction with a TRPA1 variant that does not react with our TRPA1 antibody or possibly via interaction with other irritant receptors.

\section{OC activates TRPA1 via a mechanism distinct from that of most electrophilic agonists}

To understand how OC might differ from other TRPA1 agonists with regard to the high specificity for TRPA1, we performed receptor mutagenesis and structure-activity studies. TRPA1 agonists can be divided into two basic categories related to their reactivity: electrophiles, such as AITC (Jordt et al., 2004) and many $\alpha, \beta$-unsaturated aldehydes (Macpherson et al., 2007b; Trevisani et al., 2007), and nonelectrophiles, such as carvacrol (oregano) (Xu et al., 2006). Electrophilic agonists activate TRPA1 through covalent modification of cysteine residues located within the N-terminal cytoplasmic domain of the receptor (Hinman et al., 2006; Macpherson et al., 2007a) and, to a lesser extent, through covalent binding to lysine residues (shown for AITC) (Hinman et al., 2006). The mech- anism of TRPA1 activation by nonelectrophilic agonists is presently unknown. OC is electrophilic and its structure contains a phenol ring. We asked which structural features of OC contribute to its sensory activity. We conducted structure-activity relationship (SAR) studies with synthetic oleocanthal analogs (Smith et al., 2007) using calcium imaging on dissociated rat trigeminal neurons (Fig. 7a). We found (Fig. 7b) that the saturation of the double bond dramatically decreased the potency of the molecule (A12) and, importantly, that both aldehyde groups are required to maintain OC activity (see analogs A10, 9, and 14). Although A9 is an $\alpha, \beta$-unsaturated aldehyde, and for this reason was expected to maintain sensory activity through cysteine modification of TRPA1 like other electrophilic agonists, no intracellular calcium increase was observed at $5 \mu \mathrm{M}$.

We confirmed by liquid chromatography-mass spectrometry and nuclear magnetic resonance analyses (supplemental Fig. 8 , available at www.jneurosci.org as supplemental material) that OC is capable of forming adducts to cysteine, primarily through its $\alpha, \beta$-unsaturated aldehyde moiety, but this feature does not enable OC to activate TRPA1, which distinguishes it from AITC and cinnamaldehyde.

To verify the hypothesis that OC does not activate TRPA1 via cysteine modification, we tested OC activity on a TRPA1 mutant rendered insensitive or weakly sensitive to electrophilic agonists, via substitution of two reactive cysteines (C422 and C622) by nonreactive residues (serine). Whereas cinnamaldehyde and AITC activities were abolished or strongly impaired in cells expressing the serine-substituted TRPA1 mutant, OC induced robust currents, similar to those evoked in wild-type TRPA1-expressing cells (Fig. 7c) (for parallel results, see also Escalera et al., 2008). These data confirm that OC activates the ion channel via a mechanism different from most electrophilic TRPA1 agonists, which may explain the high specificity of OC for the TRPA1 receptor expressed in pharynx and nose identified by our antibody.

\section{Discussion}

OC triggers an unusual irritation in the pharynx when ingested. Unlike most known chemical irritants, OC does not significantly irritate the oral cavity; instead, the sting is restricted to the upper airways and is often accompanied by throat clearing and coughing. Our goal in this work was to understand the molecular and physiological basis for this unique pungency. We show here that $\mathrm{OC}$, as well as ibuprofen, another compound whose irritancy is primarily restricted to the throat, activate the ion channel hTRPA1 ex vivo, and their ability to excite the trigeminal nervous system depends on functional TRPA1 in sensory neurons. Our perceptual studies in humans show that OC triggers irritation in the throat and nasal cavities with high potency compared with the anterior tongue. Consistent with the hypothesis that the OC sen- 
sory properties in vivo are the result of TRPA1 activation, immunohistochemical imaging of human tissues with hTRPA1specific antibodies revealed poor reactivity in neural fibers of the anterior tongue relative to the reactivity in neural fibers of the sensitive pharyngeal and nasal epithelia.

Previous perceptual studies have indicated that the oral mucosae along the rostrocaudal axis are not uniformly sensitive to chemical irritants (Rentmeister-Bryant and Green, 1997). The problem is that in vitro neural studies of primary sensory neurons derive primarily from analysis of complete neuronal populations prepared from whole sensory ganglia such as the trigeminal ganglion. Thus, different functional properties of primary trigeminal afferents from the different subregions of the face remain mostly uninvestigated. Using a viral tracing technique to identify nasal and cutaneous cultured mouse trigeminal neurons, Damann et al. (2006) observed a larger fraction of nasal trigeminal neurons exhibiting sensitivity for menthol and capsaicin. This indicates that neurons expressing TRPM8 and TRPV1 are not equally distributed among trigeminal fibers innervating different regions of the mouse head (Damann et al., 2006). In a comparable fashion, we showed heterogeneity of TRPA1 channel expression in human trigeminal afferents with poor expression of TRPA1 in the mandibular branch. Previous immunohistochemical studies have shown the presence of TRPA1 channel in nerve bundles of mouse tongues (Nagatomo and Kubo, 2008), in the human lingual nerve (Morgan et al., 2009). TRPA1 mRNAs have also been identified in the mandibular branch of the trigeminal nerve in mouse (Kobayashi et al., 2005). To our knowledge, however, the expression of TRPA1 channels on neuronal fibers innervating the human anterior tongue has not been reported.

As demonstrated, the concentration differences among compounds are unlikely to account for the pattern of OC irritation. Lipophilicity, and hence access to nerve fibers, also does not account for the differences in anterior tongue sensations, as AITC and OC have comparable partition coefficients. Moreover, OC is similarly effective in water and in oil. That irritation from other TRPA1 agonists is not restricted to the throat is consistent with a higher specificity of OC to the hTRPA1 channel we assessed. We demonstrated that OC does not bind to the "traditional" cysteine residues of TRPA1 that are required for cinnamaldehyde and AITC activation of TRPA1. In addition, we showed that OC differs from these other agonists in that OC requires both aldehyde groups to activate TRPA1. The selectivity for the TRPA1 channel highly expressed in nasal and pharyngeal tissues is thus likely explained by differences in how OC interacts with the channel.
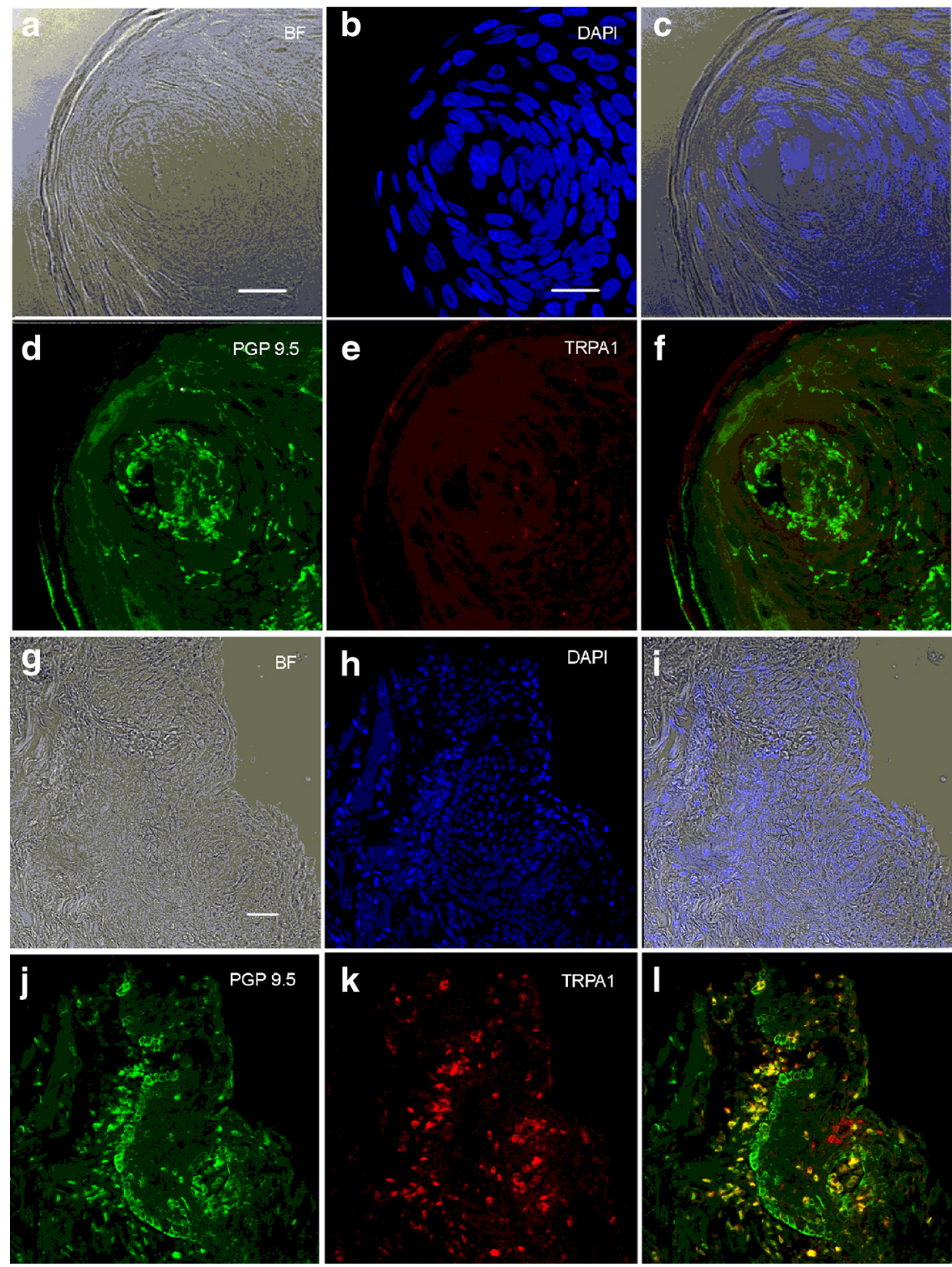

Figure 6. TRPA1 is expressed in a subset of nerve fibers in pharyngeal epithelium, but not in nerve fibers of taste buds within yellow depicts the superposition of TRPA1 reactivity (red) and neuronal PGP9.5 reactivity (green). Eight to 10 slides were examined for the pharyngeal tissue (from 1 subject) and the fungiform papilla tissue (from 4 subjects). Scale bars: $\boldsymbol{a}-\boldsymbol{f}, 20 \mu \mathrm{m} ; \boldsymbol{g}-\mathbf{I}, 40 \mu \mathrm{m}$.

Thus, the high specificity of OC for this receptor and the restricted expression pattern of the receptor underlie the unusual pungency of extra-virgin olive oil.

Our explanation for these observations is consistent with other data on receptor specificity. Many compounds presumed to be specific to a given TRP channel have subsequently been shown to activate other TRP channels involved in irritation transduction (Macpherson et al., 2006). For example, allicin can activate TRPV1 in addition to TRPA1 (Macpherson et al., 2005; Salazar et al., 2008), and cinnamaldehyde, carvacrol, and thymol are also TRPV3 agonists (Macpherson et al., 2006; Xu et al., 2006; Lee et al., 2008). In several studies, AITC-activated sensory neurons have been shown to be more numerous than those stimulated by other TRPA1 agonists such as zinc (Hu et al., 2009) or cinnamaldehyde (Bandell et al., 2004), and AITC specificity to- 
a
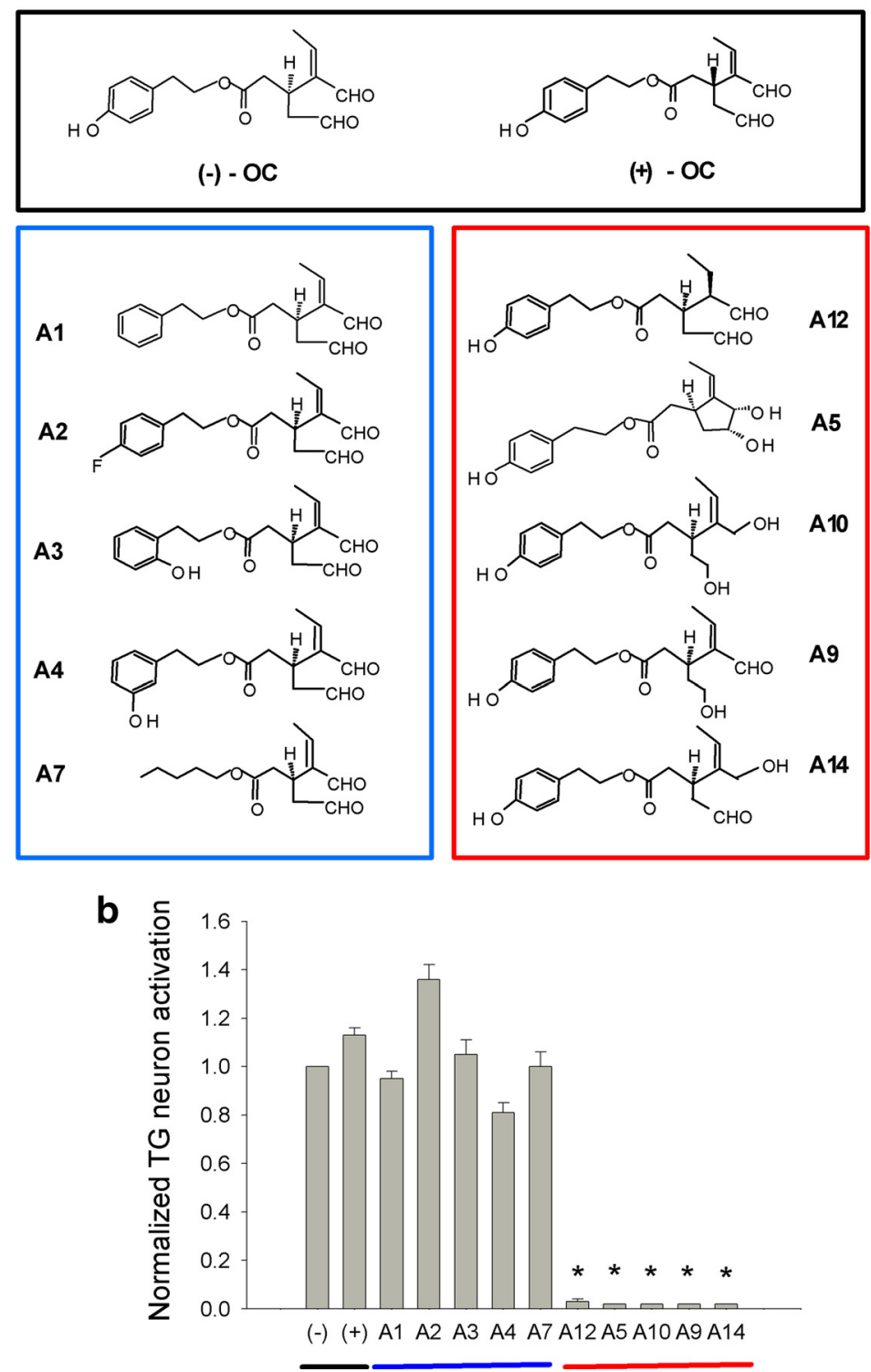

C

HEK 293 expressing TRPA1 mutants
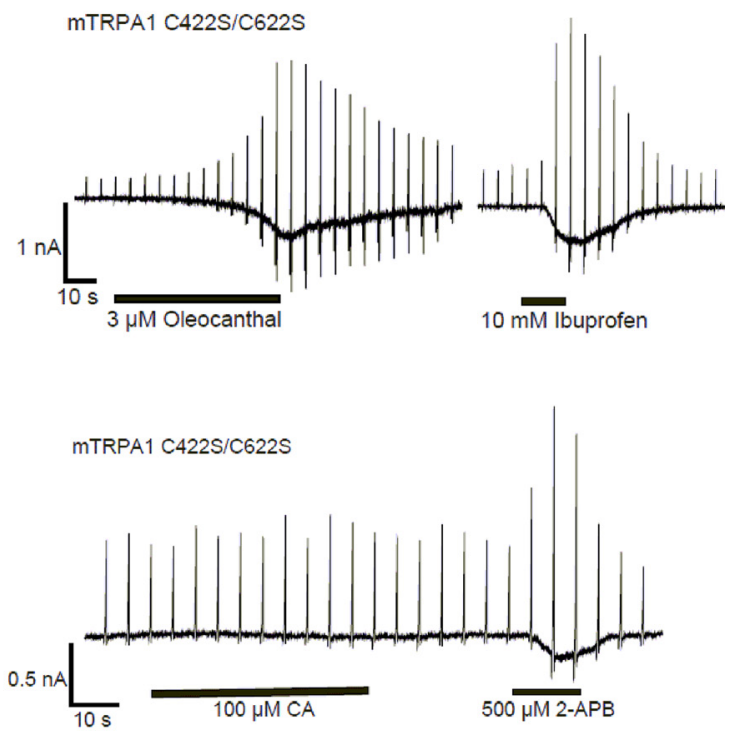

mTRPA1 C422S/C622S

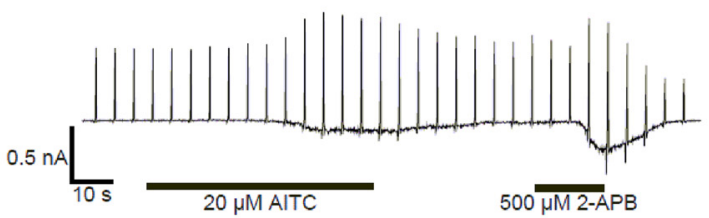

Figure 7. Structure-activity studies and receptor mutagenesis reveal a distinct mode of activation of TRPA 1 by $0 C . \boldsymbol{a}, 0$ Canalogs synthesized for $S A R$ studies. The black box displays the structures of the natural olive oil compound $[(-)-O C]$ and its enantiomer $[(+)-O C]$. The blue box regroups $O C$ analogs $(A 1,2,3,4,7)$ containing modifications of the phenol moiety and the red box regroups $O C$ analogs $(A 12,5,10,9,14)$ presenting alterations of the aldehyde functions or unsaturated bond. $\boldsymbol{b}$, The bar graph compares calcium influx elicited by $5 \mu \mathrm{m} O C$ enantiomer and analogs in rat trigeminal neurons. All ratio $\left(F_{340} / F_{380}\right)$ were normalized to the mean calcium influx induced by $5 \mu \mathrm{m} O C\left(n>123\right.$ examined cells per analog). ${ }^{*} p<0.05$ versus $(-) 0 C, t$ test. $c$, Patch-clamp experiments on mTRPA1 mutant (C422S/C622S) expressed in HEK 293 cells. Representative whole-cell current trace exposed to the electrophilic TRPA1 agonist trans-cinnamaldehyde (CA) (100 $\mu \mathrm{M}$ ) or the nonelectrophilic TRPA1 agonist 2-aminoethoxydiphenyl borate (2-APB) (500 $\mu \mathrm{m}$ ) used as a control in HEK 293 cells expressing a mutant in which cysteines at 422 and 622 were replaced with serines. Although 2-APB still has an ability to activate the mutant $(n=3)$, CA does not evoke current responses. AITC (20 $\mu \mathrm{M})$ evokes small current responses in cells expressing the mutant TRPA1 $(n=3) .0 C(3 \mu \mathrm{M})(n=4)$ and ibuprofen $(10 \mathrm{~mm})(n=4)$ induce inward currents in cells expressing TRPA1 mutant similar to those evoked in cells expressing wild-type TRPA1. Measurements were determined in the presence of extracellular $\mathrm{Ca}^{2+} \cdot V_{\mathrm{h}}=-60 \mathrm{mV}$ using a patch-clamp method. The horizontal bars indicate the duration of compound application. Error bars indicate SEM.

ward TRPA1 has been previously questioned (Bandell et al., 2004; Kwan et al., 2006). AITC has also been reported to activate porcine pTRPV1 at concentrations (in millimolar) found in food products (Ohta et al., 2007). Therefore, it is possible that sensory receptor(s) other than the hTRPA1 protein we assessed, possibly a splice variant of TRPA1, contribute to the anterior oral pungency evoked by AITC and other canonical TRPA1 ligands in humans.

What is the functional or ecological significance of the pungency to the human upper airways? One explanation is that the posterior location of toxin and irritant detectors can protect against their intake either by inhalation or ingestion. Many bitter-tasting toxins are perceived more strongly in the posterior oral cavity than the anterior (Danilova and Hellekant, 2003). For instance, the bitter iso- $\alpha$-acids from hop cone flowers found in beers stimulate taste receptors almost exclusively in the pharynx. Detection in the posterior mouth guards against intake of toxins and irritants at the last possible checkpoint. Many air pollutants such as acrolein are TRPA1 agonists (Bautista et al., 2006) and will elicit cough. Like TRPV1, TRPA1 has been shown to be expressed both in the upper and the lower airways (Fajardo et al., 2008; Nassenstein et al., 2008). Thus, TRPA1 is well positioned to protect the lungs by triggering defensive cough responses to reactive agents (Bessac and Jordt, 2008; Taylor-Clark et al., 2009). 
But if the role of these ion channels is to protect tissue from harmful compounds, then it is a mystery how the TRPA1mediated throat irritation of extra-virgin olive oils came to be valued as a positive sensory attribute by those who consume them. Indeed, this pungency is an important quality that distinguishes particularly good olive oils in the European Union standards. Similarly, other common food irritants (e.g., capsaicin, menthol, AITC, and so forth) are also important positive components in many cuisines, so this is a very general question. Pungency is believed to signal potentially harmful compounds in our food but consumption of many compounds eliciting this sensation is also linked to decreased risks of cancer and degenerative and cardiovascular diseases (Boyd et al., 2006; Peng and Li, 2010). Oleocanthal has been shown to be a potent antiinflammatory agent (Beauchamp et al., 2005), implicating potential medicinal value to this compound. It is, therefore, perhaps no coincidence that the only other known restricted throat irritants are NSAID molecules such as ibuprofen. At least in the case of extra-virgin olive oils, we suggest that by a process not yet well understood people have come, perhaps unconsciously, to transform an inherently unpleasant sensation into a positive one because it has beneficial health effects (Peyrot des Gachons et al., 2009). This broad speculation requires considerably more investigation before it can be demonstrated.

\section{References}

Andrewes P, Busch JL, de Joode T, Groenewegen A, Alexandre H (2003) Sensory properties of virgin olive oil polyphenols: identification of deacetoxy-ligstroside aglycon as a key contributor to pungency. J Agric Food Chem 51:1415-1420.

Bandell M, Story GM, Hwang SW, Viswanath V, Eid SR, Petrus MJ, Earley TJ, Patapoutian A (2004) Noxious cold ion channel TRPA1 is activated by pungent compounds and bradykinin. Neuron 41:849-857.

Bautista DM, Movahed P, Hinman A, Axelsson HE, Sterner O, Högestätt ED, Julius D, Jordt SE, Zygmunt PM (2005) Pungent products from garlic activate the sensory ion channel TRPA1. Proc Natl Acad Sci U S A 102:12248-12252.

Bautista DM, Jordt SE, Nikai T, Tsuruda PR, Read AJ, Poblete J, Yamoah EN, Basbaum AI, Julius D (2006) TRPA1 mediates the inflammatory actions of environmental irritants and proalgesic agents. Cell 124:1269-1282.

Beauchamp GK, Keast RS, Morel D, Lin J, Pika J, Han Q, Lee CH, Smith AB, Breslin PA (2005) Phytochemistry: ibuprofen-like activity in extravirgin olive oil. Nature 437:45-46.

Bessac BF, Jordt SE (2008) Breathtaking TRP channels: TRPA1 and TRPV1 in airway chemosensation and reflex control. Physiology (Bethesda) 23:360-370.

Boyd LA, McCann MJ, Hashim Y, Bennett RN, Gill CI, Rowland IR (2006) Assessment of the anti-genotoxic, anti-proliferative, and anti-metastatic potential of crude watercress extract in human colon cancer cells. Nutr Cancer 55:232-241.

Brand G, Jacquot L (2002) Sensitization and desensitization to allyl isothiocyanate (mustard oil) in the nasal cavity. Chem Senses 27:593-598.

Breslin PA, Gingrich TN, Green BG (2001) Ibuprofen as a chemesthetic stimulus: evidence of a novel mechanism of throat irritation. Chem Senses 26:55-65.

Carluccio MA, Siculella L, Ancora MA, Massaro M, Scoditti E, Storelli C, Visioli F, Distante A, De Caterina R (2003) Olive oil and red wine antioxidant polyphenols inhibit endothelial activation: antiatherogenic properties of Mediterranean diet phytochemicals. Arterioscler Thromb Vasc Biol 23:622-629.

Caterina MJ, Schumacher MA, Tominaga M, Rosen TA, Levine JD, Julius D (1997) The capsaicin receptor: a heat-activated ion channel in the pain pathway. Nature 389:816-824.

Chen J, Zhang XF, Kort ME, Huth JR, Sun C, Miesbauer LJ, Cassar SC, Neelands T, Scott VE, Moreland RB, Reilly RM, Hajduk PJ, Kym PR, Hutchins CW, Faltynek CR (2008) Molecular determinants of speciesspecific activation or blockade of TRPAl channels. J Neurosci 28:5063-5071.

Clapham DE (2003) TRP channels as cellular sensors. Nature 426:517-524.
Damann N, Rothermel M, Klupp BG, Mettenleiter TC, Hatt H, Wetzel CH (2006) Chemosensory properties of murine nasal and cutaneous trigeminal neurons identified by viral tracing. BMC Neurosci 7:46.

Danilova V, Hellekant G (2003) Comparison of the responses of the chorda tympani and glossopharyngeal nerves to taste stimuli in C57BL/6J mice. BMC Neurosci 4:5.

Escalera J, von Hehn CA, Bessac BF, Sivula M, Jordt SE (2008) TRPA1 mediates the noxious effects of natural sesquiterpene deterrents. J Biol Chem 283:24136-24144.

Fajardo O, Meseguer V, Belmonte C, Viana F (2008) TRPA1 channels mediate cold temperature sensing in mammalian vagal sensory neurons: pharmacological and genetic evidence. J Neurosci 28:7863-7875.

Green BG, Dalton P, Cowart B, Shaffer G, Rankin K, Higgins J (1996) Evaluating the "Labeled Magnitude Scale" for measuring sensations of taste and smell. Chem Senses 21:323-334.

Hinman A, Chuang HH, Bautista DM, Julius D (2006) TRP channel activation by reversible covalent modification. Proc Natl Acad Sci U S A 103:19564-19568.

Hu H, Bandell M, Petrus MJ, Zhu MX, Patapoutian A (2009) Zinc activates damage-sensing TRPA1 ion channels. Nat Chem Biol 5:183-190.

Jordt SE, Bautista DM, Chuang HH, McKemy DD, Zygmunt PM, Högestätt ED, Meng ID, Julius D (2004) Mustard oils and cannabinoids excite sensory nerve fibres through the TRP channel ANKTM1. Nature 427:260-265.

Kobayashi K, Fukuoka T, Obata K, Yamanaka H, Dai Y, Tokunaga A, Noguchi K (2005) Distinct expression of TRPM8, TRPA1, and TRPV1 mRNAs in rat primary afferent neurons with adelta/c-fibers and colocalization with trk receptors. J Comp Neurol 493:596-606.

Kwan KY, Allchorne AJ, Vollrath MA, Christensen AP, Zhang DS, Woolf CJ, Corey DP (2006) TRPA1 contributes to cold, mechanical, and chemical nociception but is not essential for hair-cell transduction. Neuron 50:277-289.

Lee SP, Buber MT, Yang Q, Cerne R, Cortés RY, Sprous DG, Bryant RW (2008) Thymol and related alkyl phenols activate the hTRPAl channel. Br J Pharmacol 153:1739-1749.

Levine JD, Alessandri-Haber N (2007) TRP channels: targets for the relief of pain. Biochim Biophys Acta 1772:989-1003.

Macpherson LJ, Geierstanger BH, Viswanath V, Bandell M, Eid SR, Hwang S, Patapoutian A (2005) The pungency of garlic: activation of TRPA1 and TRPV1 in response to allicin. Curr Biol 15:929-934.

Macpherson LJ, Hwang SW, Miyamoto T, Dubin AE, Patapoutian A, Story GM (2006) More than cool: promiscuous relationships of menthol and other sensory compounds. Mol Cell Neurosci 32:335-343.

Macpherson LJ, Dubin AE, Evans MJ, Marr F, Schultz PG, Cravatt BF, Patapoutian A (2007a) Noxious compounds activate TRPA1 ion channels through covalent modification of cysteines. Nature 445:541-545.

Macpherson LJ, Xiao B, Kwan KY, Petrus MJ, Dubin AE, Hwang S, Cravatt B, Corey DP, Patapoutian A (2007b) An ion channel essential for sensing chemical damage. J Neurosci 27:11412-11415.

McKemy DD, Neuhausser WM, Julius D (2002) Identification of a cold receptor reveals a general role for TRP channels in thermosensation. Nature 416:52-58.

McNamara CR, Mandel-Brehm J, Bautista DM, Siemens J, Deranian KL, Zhao M, Hayward NJ, Chong JA, Julius D, Moran MM, Fanger CM (2007) TRPA1 mediates formalin-induced pain. Proc Natl Acad Sci U S A 104:13525-13530.

Morgan CR, Bird EV, Robinson PP, Boissonade FM (2009) TRPA1 expression in human lingual nerve neuromas in patients with and without symptoms of dysaesthesia. Neurosci Lett 465:189-193.

Nagatomo K, Kubo Y (2008) Caffeine activates mouse TRPA1 channels but suppresses human TRPAl channels. Proc Natl Acad Sci USA 105:17373-17378.

Nassenstein C, Kwong K, Taylor-Clark T, Kollarik M, Macglashan DM, Braun A, Undem BJ (2008) Expression and function of the ion channel TRPA1 in vagal afferent nerves innervating mouse lungs. J Physiol 586:1595-1604.

Ohta T, Imagawa T, Ito S (2007) Novel agonistic action of mustard oil on recombinant and endogenous porcine transient receptor potential V1 (pTRPV1) channels. Biochem Pharmacol 73:1646-1656.

Peier AM, Moqrich A, Hergarden AC, Reeve AJ, Andersson DA, Story GM, Earley TJ, Dragoni I, McIntyre P, Bevan S, Patapoutian A (2002) A TRP channel that senses cold stimuli and menthol. Cell 108:705-715. 
Peng J, Li YJ (2010) The vanilloid receptor TRPV1: role in cardiovascular and gastrointestinal protection. Eur J Pharmacol 627:1-7.

Perez-Jimenez F, Alvarez de Cienfuegos G, Badimon L, Barja G, Battino M, Blanco A, Bonanome A, Colomer R, Corella-Piquer D, Covas I, Chamorro-Quiros J, Escrich E, Gaforio JJ, Garcia Luna PP, Hidalgo L, Kafatos A, Kris-Etherton PM, Lairon D, Lamuela-Raventos R, LopezMiranda J, et al. (2005) International conference on the healthy effect of virgin olive oil. Eur J Clin Invest 35:421-424.

Peyrot des Gachons C, Beauchamp GK, Breslin PA (2009) The genetics of bitterness and pungency detection and its impact on phytonutrient evaluation. Ann N Y Acad Sci 1170:140-144.

Rentmeister-Bryant H, Green BG (1997) Perceived irritation during ingestion of capsaicin or piperine: comparison of trigeminal and nontrigeminal areas. Chem Senses 22:257-266.

Salazar H, Llorente I, Jara-Oseguera A, García-Villegas R, Munari M, Gordon SE, Islas LD, Rosenbaum T (2008) A single N-terminal cysteine in TRPV1 determines activation by pungent compounds from onion and garlic. Nat Neurosci 11:255-261.

Smith AB 3rd, Han Q, Breslin PA, Beauchamp GK (2005) Synthesis and assignment of absolute configuration of $(-)$-oleocanthal: a potent, naturally occurring non-steroidal anti-inflammatory and anti-oxidant agent derived from extra virgin olive oils. Org Lett 7:5075-5078.

Smith AB 3rd, Sperry JB, Han Q (2007) Syntheses of (-)-oleocanthal, a natural NSAID found in extra virgin olive oil, the $(-)$-deacetoxyoleuropein aglycone, and related analogues. J Org Chem 72:68916900.

Taylor-Clark TE, Nassenstein C, McAlexander MA, Undem BJ (2009) TRPA1: a potential target for anti-tussive therapy. Pulm Pharmacol Ther 22:71-74.

Trevisani M, Siemens J, Materazzi S, Bautista DM, Nassini R, Campi B, Imamachi N, Andrè E, Patacchini R, Cottrell GS, Gatti R, Basbaum AI, Bunnett NW, Julius D, Geppetti P (2007) 4-Hydroxynonenal, an endogenous aldehyde, causes pain and neurogenic inflammation through activation of the irritant receptor TRPA1. Proc Natl Acad Sci U S A 104:13519-13524.

Xu H, Delling M, Jun JC, Clapham DE (2006) Oregano, thyme and clovederived flavors and skin sensitizers activate specific TRP channels. Nat Neurosci 9:628-635. 